\title{
Probabilistic modelling of exposure to pesticide residues in foods and tobacco
}

\author{
Lukyn M. Gedge ${ }^{1}$, Iwona Hawryluk, Mary G. Skelly ${ }^{1}$, Giulia Vilone
}

\author{
${ }^{1}$ Microbide Limited, Ireland, 28 Village Mill Business Park, Rathnew, County Wicklow, A67 CP20, Ireland \\ Corresponding Author: Lukyn M. Gedge
}

\begin{abstract}
Background: Several pesticides are currently available on the US market and used on different crops that enter into the human food chain or are used in consumer products, such as food and cigarettes. Some of these pesticides are classified as toxic or carcinogenic to humans. Additionally, little is known about the combined effects of concurrent exposure events. Hence, it is of paramount importance to develop ways to estimate the cumulative, i.e. multi-chemical, exposure to these substances. This study presents a novel approach to estimate the cumulative exposure of the US population to pesticide residues via two routes, foods and tobacco.
\end{abstract}

Methods: Cumulative dietary exposure assessment was run using CARES NG® cloud-based software. Calculations were based on the National Health and Nutrition Examination Survey (NHANES) consumption surveys and incorporated the residue monitoring data from the Pesticide Data Program (PDP) database. A two-box model and smoking habits recorded in the NHANES survey were used to calculate the exposure to pesticide residues from smoking cigarettes.

Results: The results of both models were combined to estimate the total aggregate and cumulative exposure. The outcomes show that although the exposure levels are well below the regulatory limits, the exposure among children is higher than among adult smokers on the $99^{\text {th }}$ percentile level. Moreover, the exposure in the adult population is twice as high for smokers than non-smokers. Among the studied pesticides, chlorpyrifos is the pesticide with the highest exposure levels.

Conclusions: The model described in this manuscript provides a new general framework, that can be used to assess the impact of a new pesticide on the population in a broader spectrum than the models typically used for such purpose. To our knowledge, it is the first model that combines the estimation of the pesticide exposure from the diet and smoking cigarettes.

Keywords-pesticide residues, cumulative exposure, CARES NG®, PDP, probabilistic modelling, chlorpyrifos.

\section{BACKGROUND}

Pesticide usage on crops to protect them from insects, rodents and fungi is part of modern life. By their nature, pesticides can be toxic to organisms beyond their target, including humans $[1,2]$. Occupationally exposed individuals and those in the immediate area of pesticide application are most at risk of exposure [3]. However, traces of pesticides remaining on the agricultural commodities used as food pose another risk, as many of these chemicals have carcinogenic or toxic classifications [4]. Low dose chronic exposure, through domestic use as well as consuming foods and drinking water, has been observed and linked to possible adverse health effects, such as endocrine disruptions, cancer or negative effects on neurodevelopment and reproductive system [5, 6]. Children are at particular risk of exposure for several reasons, including that children consume more foods relative to their body weight than adults do [7]. Due to these risks related to the dietary exposure to pesticide residues, it is of utmost importance to regularly monitor the exposure levels in the population.

Organophosphate pesticides (OPs) are the most commonly used insecticides globally today [8]. They are applied to many different foods and crops and are also licensed for domestic use in products applied in and around houses, such as insect repellents and indoor/outdoor foggers. Metabolites of OPs were found in $96 \%$ of urine sampled in a study on the US 
general population, suggesting a widespread chronic low dose exposure [9].

This is most likely caused by the dietary exposure, as increased fruit and vegetable consumption is associated with higher levels of these metabolites [10,11].

Recent studies have raised concerns regarding low dose chronic OPs exposure and child neurodevelopment outcomes. Increased likelihood of autism or ADHD was associated with the higher concentration of OPs metabolites in utero or in early childhood [11, 12]. Another study in the US found that every 522 pounds of OPs applied within $1 \mathrm{~km}$ of a pregnant woman's home correlates to a loss of two IQ points in her child at age 7 [13]. One of the most toxic organophosphates currently used on the agricultural market is chlorpyrifos. In 2018, the federal court in the US has ordered the Environmental Protection Agency (EPA) to ban chlorpyrifos, due to its potential link to development of learning difficulties in children [14].Although numerous studies relate to dietary exposure to pesticide residues, little is known about the combined effects of concurrent, i.e. multi-source, exposure events $[15,16]$.

The literature suggests that smoking is another chronic pesticide exposure route. The traces of the pesticides used on tobacco leaves are present in the dried tobacco used in cigarettes, and effectively burnt along with tobacco and other additives to be inhaled by both active and passive smokers [17, 18]. Similar risks are related to smoking marijuana [19], making both tobacco and marijuana two sources of pesticide exposure in the general population that might increase the risk of adverse health-effects. Despite this, there is no model for quantifying the amounts of inhaled pesticides to which the smokers are exposed. Hence, it is of paramount importance to develop ways to estimate the cumulative, i.e. multi-chemical, exposure to the pesticide residues in dietary sources combined with the exposure to pesticide residues that might be inhaled while smoking.
This study aimed to develop a framework that facilitates the estimation and understanding of the cumulative exposure to pesticide residues on the US population. The model presented in this manuscript proposes a novel probabilistic approach to modelling exposure to pesticide residues via two routes, diet and smoking cigarettes. Long-term dietary exposure was calculated with the CARES NG® cloud-based probabilistic software model which facilitates multi-source, multi-route aggregate (for individual chemicals) and cumulative (for multiple chemicals) exposure and risk assessments [20]. The quantities of pesticide residues inhaled while smoking cigarettes were estimated with a two-box model, primarily developed by RIFM (Research Institute of Fragrance Materials) for assessing the exposure to fragrance materials [21]. The framework was applied on a range of foods and pesticides, including some OPs. The main scope of this analysis was to check whether the framework returns realistic exposure estimates when applied to the real-world data. The proposed framework can be a starting point for further and more refined analyses of the cumulative exposure to pesticide coming from various sources and used as a tool not only for getting a better understanding of the current exposure levels, but also for assessing the impact or a need for new pesticides coming onto the market.

\section{METHODS}

We combined the US National Health and Nutrition Examination Survey (NHANES) data [22] with monitoring data from the Pesticide Data Program (PDP) [23], which provides information about the pesticide residue levels in foods sold on the American market. Five food commodities were chosen as a subset of the total diet: strawberries, tomatoes, lettuce, apples and rice. The dietary exposure assessment was performed with the CARES NG® model. The quantities of pesticide residues inhaled while smoking cigarettes were calculated for the same NHANES subjects

Table 1 NHANES 2005-2010 population summary.

\begin{tabular}{cllllll}
\hline Group & $\begin{array}{l}\text { Age range } \\
\text { (years) }\end{array}$ & Gender & $\begin{array}{l}\text { Mean body } \\
\text { weight }[\mathrm{kg}]\end{array}$ & Subject count & Smokers count & $\%$ of smokers \\
\hline Children & $0-18$ & Males & 40.9 & 5,272 & 188 & $3.6 \%$ \\
\cline { 2 - 6 } & & Females & 38.8 & 5,155 & 173 & $3.3 \%$ \\
\hline Adults & $19-85$ & Males & 88.9 & 6,789 & 1,673 & $25 \%$ \\
\cline { 2 - 6 } & & Females & 75.7 & 7,457 & 1,338 & $18 \%$ \\
\hline
\end{tabular}


using their smoking habits data and the two-box model, used previously for assessing exposure to fragrance materials and developed by RIFM. All data used in this project is publicly available.

\section{Consumption data}

What We Eat In America (WWEIA) is a national 2-day food consumption survey, part of the US National Health and Nutrition Examination Survey (NHANES), an annual program conducted by the National Centre for Health Statistics (NCHS) [24]. It combines interviews and medical examinations designed to assess the health and nutritional status of adults and children in the US. The U.S. EPA's Office of Pesticide Programs (OPP) developed the Food Commodity Intake Database (FCID) to translate foods "as eaten", reported in NHANES, to a food commodity basis. FCID uses recipe files to break down all foods into their raw agricultural commodity (RAC) equivalents. WWEIA data is expressed as grams of food commodity consumed per kg body weight per day for over 500 commodities derived from more than 7,000 different foods and beverages. In this study, a merged version of WWEIA/NHANES surveys from 2005 - 2010 was used, containing demographic data for 24,673 subjects, such as body weight, gender, age, two-day food consumption diary based on 24-hour recall data, and smoking habits of each subject including the average number of cigarettes smoked per day in the last 30 days. Each subject had a statistical weight assigned in order to make the sample of the subjects more representative of the total population, increasing the reliability and precision of the results. The NHANES population was divided into 4 age and gender subgroups, as shown in Table 1 .

\section{Pesticide residues in foods}

Data related to the pesticide residues in strawberries, tomatoes, lettuce, apples and rice was obtained from the Pesticide Data Program (PDP) database [23]. PDP is a national pesticide residue monitoring program and produces the most comprehensive pesticide residue database in the US. It contains the residue data collected annually in the US from 1994 to 2016. In this project, we focused only on data from 2005-2015.

PDP commodity sampling is based on a rigorous statistical design ensuring that the data is reliable for use in the exposure assessments. The pesticides and commodities to be analysed each year are selected based on the US Environmental Protection Agency (EPA) data needs and taking into account types and amounts of food consumed by infants and children. The number of samples collected by each state is apportioned according to that state's population. Samples are randomly chosen and reflect what is typically available to the consumer throughout the year.

Given the variety of pesticides applied to the US crops, the estimation of the exposure levels from all pesticides would not bring meaningful results. Hence, only a few pesticides for each food group and tobacco were analysed. The pesticides with the highest chances to have adverse effects on people's health for each group were chosen, by selecting the most toxic pesticides with the highest numbers of samples recorded in PDP that contained detected pesticide residue. The sold quantities of each pesticide were also checked to avoid analysing pesticides that are rarely used[16]. Selected pesticides per each commodity and an overview of the data obtained from PDP are given in Table 3.

Table 2 NHANES 2005-2010 adults; smoking habits. Range of cigarettes smoked per smoker was 1-95 per person.

\begin{tabular}{llllll} 
& & & per day & per day & per day \\
\hline Males & Smokers & 1,673 & 15.69 & 40 & 60 \\
\cline { 2 - 6 } & Total population & 6,789 & 3.86 & 20 & 40 \\
\hline \multirow{2}{*}{ Females } & Smokers & 1,338 & 13.87 & 30 & 44 \\
\cline { 2 - 6 } & Total population & 7,457 & 2.66 & 20 & 30 \\
\hline
\end{tabular}


International Journal of Environment, Agriculture and Biotechnology, 5(2)

Available: https://ijeab.com/

Table 3 Pesticides chosen for comparison, food commodities; summary of PDP data, combined for years 2005-2015.

\begin{tabular}{|c|c|c|c|c|c|c|}
\hline Commodity & $\begin{array}{l}\text { Pesticides } \\
\text { considered }\end{array}$ & $\begin{array}{l}\text { Number of } \\
\text { samples in PDP } \\
\text { containing } \\
\text { residues }\end{array}$ & $\begin{array}{l}\text { Total number of } \\
\text { samples in PDP }\end{array}$ & $\begin{array}{l}\text { Maximum } \\
\text { concentration of } \\
\text { pesticide detected } \\
{[\mathrm{ppm}]}\end{array}$ & MRL [ppm] & $\begin{array}{l}\% \text { of } \\
\text { samples } \\
\text { from US }\end{array}$ \\
\hline \multirow[t]{4}{*}{ Strawberries } & Chlorpyrifos & 52 & 3104 & 0.130 & 0.2 & \multirow[t]{4}{*}{$90 \%$} \\
\hline & Thiamethoxam & 259 & 2367 & 0.250 & 0.3 & \\
\hline & Novaluron & 199 & 882 & 0.390 & 0.45 & \\
\hline & Pyriproxyfen & 26 & 2583 & 0.079 & 0.5 & \\
\hline \multirow[t]{4}{*}{ Tomatoes } & Chlorpyrifos & 35 & 2366 & 0.055 & 0.5 & \multirow[t]{4}{*}{$58 \%$} \\
\hline & Bifenthrin & 221 & 2347 & 0.110 & 0.15 & \\
\hline & Azoxystrobin & 372 & 2366 & 0.059 & 0.2 & \\
\hline & Pyriproxyfen & 81 & 2366 & 0.079 & 0.8 & \\
\hline \multirow[t]{3}{*}{ Lettuce } & Chlorpyrifos & 18 & 1403 & 0.078 & 1 & \multirow[t]{3}{*}{$98 \%$} \\
\hline & Diazinon & 93 & 1275 & 0.027 & 0.7 & \\
\hline & Imidacloprid & 640 & 1403 & 0.190 & 3.5 & \\
\hline \multirow[t]{3}{*}{ Apples } & Chlorpyrifos & 30 & 3116 & 0.145 & 0.01 & \multirow[t]{3}{*}{$95 \%$} \\
\hline & Diazinon & 161 & 3116 & 0.210 & 0.5 & \\
\hline & Imidacloprid & 612 & 3116 & 0.051 & 0.5 & \\
\hline \multirow[t]{3}{*}{ Rice } & Malathion & 16 & 933 & 0.043 & 8 & \multirow[t]{3}{*}{$83 \%$} \\
\hline & MGK-264 & 66 & 933 & 1.439 & $*$ & \\
\hline & $\begin{array}{l}\text { Piperonyl } \\
\text { butoxide }\end{array}$ & 165 & 933 & 20.85 & $*$ & \\
\hline
\end{tabular}

* No MRLs for MGK-264 and piperonyl butoxide in rice were found at the time of the study.

All detected quantities of the pesticides concentrations were below the allowed Maximum Residue Levels (MRLs), which is the highest legally allowed level of a pesticide residue in or on food or feed [4]. The MRLs considered for inclusion in the study presented here are based on availability and knowledge of the participating authors. The data registered by PDP shows that the majority of the agricultural commodities consumed by the US population is of domestic origin.

\section{Pesticide residues in tobacco}

Tobacco is not considered to be a food commodity, so the crops are not included in the PDP. The EPA also does not set the maximum residue levels of pesticide residues on tobacco in the US [25]. Information on the typical pesticide residue values that can be measured on tobacco and toxicology limits were searched for in the scientific literature. However, the studies reporting quantities of pesticide residues in tobacco focus on testing the laboratory method used to estimate the residues rather than providing data on the residues that can be typically found on tobacco. Hence, these data cannot be considered suitable for exposure analyses. For the purpose of this study, the typical residue levels in tobacco were approximated with the Guidance Residue Levels (GRLs), provided by CORESTA (Cooperation Centre for Scientific Research Relative to Tobacco)[26].

In this study, 3 organophosphates with the lowest GRL values were included in the analysis: chlorpyrifos, parathion and terbufos, outlined in Table 4. 
Table 4 The organophosphates used on tobacco crops included in the analysis.

\begin{tabular}{ll}
\hline Pesticide name & GRL [ppm] \\
\hline Chlorpyrifos & 0.5 \\
\hline Parathion & 0.06 \\
\hline Terbufos & 0.05 \\
\hline
\end{tabular}

\section{CARES NG®}

The Cumulative and Aggregate Risk Evaluation System New Generation (CARES NG®) is a cloud-based software providing probabilistic modelling of exposure and risk assessments [20]. CARES NG® allows one to run aggregate and cumulative exposure assessments using methods following the current US EPA Office of Pesticide Program (OPP) guidelines [27, 28]. The software is available for public use online at caresng.org.

CARES NG® Dietary Model estimates dietary exposure from pesticide residues in food using NHANES subject data and PDP pesticide residue data. The model is capable of estimating the typical dietary patterns of the US population over the different time frames, from acute, single-day to long-term, chronic exposure. In this study, multi-day exposure was of interest. The multi-day assessment uses the entire available residue distribution, by randomly selecting a residue value from the distribution for each consumption event reported in the NHANES survey.

The dietary module incorporates the EPA/OPP guidance for adjusting residue values based on the percentage of crop treated and residue type. The Percentage of Crop treated of each commodity was set to $100 \%$ for all RACs, hence according to the guidance all the non-detects should be modified. However, the rules set by the guidance are not applicable in the cumulative assessment, because it is necessary to preserve the co-occurrence of the different pesticides in the analysed food samples. This information is stored in the PDP database by assigning a sample number to each residue data point. Therefore, the rules were not applied, and no changes were made to the input residue data. CARES NGß Dietary Model allows the usage of modification factors that account for increase or decrease in residues in foods or in water due to preparation (i.e. washing, cooking, peeling) or treatment (i.e. filtration, chlorination). Modification factors were also included in the analysis and were set to default values established by the EPA[28].

For cumulative assessment, chlorpyrifos was used as the Index Chemical, providing a point of reference from which the toxic potencies for all chemicals were standardised. For each pesticide, MRLs were used as Points of Departure (POD) and Uncertainty Factor was set to 100 by default as per EPA recommendation [27], to account for inter- and intra-species differences in relation to the toxic effects.

Table 5 Toxicology limits of the chemicals analysed in the dietary assessments.

\begin{tabular}{llll}
\hline Chemical Name & CAS number & $\begin{array}{l}\text { Point of Departure } \\
{[\mathrm{ppm}](\mathrm{MRL})}\end{array}$ & $\begin{array}{l}\text { Relative Potency Factor } \\
(\mathrm{RPF})\end{array}$ \\
\hline Chlorpyrifos & $2921-88-2$ & 0.01 & 1 \\
\hline Diazinon & $333-41-5$ & 0.5 & 0.020 \\
\hline Imidacloprid & $138261-41-3$ & 0.5 & 0.020 \\
\hline Azoxystrobin & $131860-33-8$ & 0.2 & 0.050 \\
\hline Bifenthrin & $82657-04-3$ & 0.15 & 0.067 \\
\hline Malathion & $121-75-5$ & 8 & 0.001 \\
\hline MGK-264 & $113-48-4$ & 0.5 & 0.020 \\
\hline Piperonyl Butoxide & $51-03-6$ & 0.5 & 0.020 \\
\hline Novaluron & $116714-46-6$ & 0.45 & 0.022 \\
\hline Thiamethoxam & $153719-23-4$ & 0.3 & 0.033 \\
\hline Pyriproxyfen & $95737-68-1$ & 0.3 & 0.033 \\
\hline
\end{tabular}


If MRL was different for a pesticide depending on a crop (e.g. chlorpyrifos for strawberries and apples), a minimum value was used as a POD. These values were used to calculate Relative Potency Factors, which the exposure to each chemical was multiplied by in order to determine the Exposure Equivalents in terms of Index Chemical (chlorpyrifos in this study).

Details of pesticides analysed and the parameter values applied are shown in Table 5.

\section{Two-box model for inhalation exposure}

An alternative model to assess the inhalation exposure to tobacco from smoking had to be proposed, as the CARES NG® Dietary Model analyses only exposure from pesticide residues in food and drinking water. To the best of our knowledge, no published model estimates the exposure to pesticide residues from smoking tobacco. Additionally, no studies have been published on the amounts of pesticides from tobacco that are directly inhaled while smoking. Therefore, we propose to use the two-box model [21], developed by Research Institute of Fragrance Materials (RIFM) for assessing exposure to fragrance materials in sprays, perfume, scented candles, etc. In the case of sprays as well as smoking, the exposure to the chemical is happening via inhalation route and there is a single source (e.g. perfume/cigarette) that releases the chemical over a certain period of time, therefore the same model can be applied.

The two-box model describes the change of the concentration of the chemical of interest (here, pesticide residue) in two zones, where Zone 1 is contained in Zone 2 (e.g. zone 1 bathroom, zone 2 - house). The model takes into account number of parameters, e.g. volumes of both zones, mass of the material of interest, air-flow between the two zones and the outside (ventilation). Moreover, the two-box model allows modelling the situation in which the subject moves from Zone 1 to the surrounding Zone 2 after a specified time. In the case of smoking a cigarette, Zone 1 is a "breathing zone" around the smoker's head $\left(1 \mathrm{~m}^{3}\right)$ and Zone 2 is a room in which the subject smokes (e.g. a living room), and where the subject stays after smoking the cigarette. For conservative reasons, it was assumed that all the smoking events occurs indoor, i.e. the subjects smoke only within their houses. The subject is in the Zone 1 for the time of smoking a cigarette - 6 minutes - and then moves to Zone 2, where he/she stays for another 40 minutes (these and other parameters were obtained from scientific studies and are listed together with corresponding references in the Supplementary Material [Additional file 1]).

The concentration of the chemical in the air is multiplied by the inhalation rate, giving as a result the inhaled dose of the chemical. This value is an inhaled dose per cigarette, which then can be multiplied by the average number of cigarettes per day (this value is subject-specific and comes directly from NHANES data) to obtain the absolute exposure per day.

The two-box model does not directly incorporate the active inhalation when smoking a cigarette, i.e. "puffing". However, it is presenting a conservative approach, as it uses the inhalation rate recommended by US EPA for high-intensity activity level during smoking and afterwards [29]. Moreover, this model does not take into account using a cigarette filter and assumes that $100 \%$ of the pesticide residue present on the tobacco leaf is transferred into the smoke[30]. The impact of the cigarette filter on the inhalation of pesticides residues is however unknown and there exists no scientific evidence that using the filter decreases the exposure levels.

Toxicological information about pesticides used in the smoking exposure assessment is presented in Table 6. RPFs were calculated in the same way as for the dietary assessment, with the Uncertainty Factors set to 100

Table 6 Toxicology limits of the chemicals analysed in the inhalation assessments.

\begin{tabular}{llll}
\hline Chemical Name & CAS number & $\begin{array}{l}\text { Point of Departure [ppm] } \\
(\text { GRL })\end{array}$ & $\begin{array}{l}\text { Relative Potency Factor } \\
(\text { RPF })\end{array}$ \\
\hline Chlorpyrifos & $2921-88-2$ & 0.5 & 1 \\
\hline Parathion & $056-38-2$ & 0.06 & 8.33 \\
\hline Terbufos & $13071-79-9$ & 0.05 & 10 \\
\hline
\end{tabular}


International Journal of Environment, Agriculture and Biotechnology, 5(2)

Available: https://ijeab.com/

Table 7 Contribution of food groups to the total average diet; NHANES 2005-2015 consumption surveys.

\begin{tabular}{lllllll}
\hline Commodity & Children male* & $\begin{array}{l}\text { Children } \\
\text { female }\end{array}$ & $\begin{array}{l}\text { Children } \% \text { of } \\
\text { total diet }\end{array}$ & $\begin{array}{c}\text { Adults male* } \\
\text { Adults female* }\end{array}$ & $\begin{array}{c}\text { Adults } \% \text { of } \\
\text { total diet }\end{array}$ \\
\hline Strawberry & 0.29 & 0.27 & $0.73 \%$ & 0.08 & 0.12 & $0.67 \%$ \\
\hline Tomato & 1.03 & 0.97 & $2.59 \%$ & 0.74 & 0.68 & 0.27 \\
\hline Lettuce & 0.15 & 0.18 & $0.42 \%$ & 0.44 & 0.47 & $3.08 \%$ \\
\hline Apple & 2.97 & 3.13 & $7.94 \%$ & 0.30 & 0.18 & $1.61 \%$ \\
\hline Rice & 0.34 & 0.35 & $0.90 \%$ & 13.55 & 12.70 & $88.25 \%$ \\
\hline Rest of diet & 35.07 & 32.28 & $87.41 \%$ & & \\
\hline
\end{tabular}

*Given in g/kg-day

\section{Total assessment}

To obtain the cumulative exposure which the US population is subjected to,exposure levels from both foods and tobacco had to be combined. This was possible because both assessments were based on the same list of subjects, i.e. the participants to the NHANES survey. The amounts of pesticides consumed/inhaled were added on a subject level, matching the exposure from consumed foods and smoking by the subject ID.

\section{RESULTS}

The outcomes are given as both aggregate and cumulative exposure assessment. Cumulative results are expressed in terms of exposure to chlorpyrifos, which is one of the pesticides analysed in this study and was selected as an index chemical, i.e. point of reference from which the toxic potencies of the other pesticides can be standardised.

\section{Dietary exposure}

The present study looked only at a limited number of food groups which contribute overall to less than $15 \%$ of a typical American diet (based on the NHANES 2005 -2010 population), as shown in Table 7. This means that all $\mathrm{t}$ presented in this manuscript represent only a portion of the dietary exposure sources that can affect the US population.

The results of the cumulative dietary assessment are given in Table 8. Chronic Reference Dose (cRfD) is given as a point of comparison. cRfD is a daily oral exposure of a chemical to the human population that is likely to be without an appreciable risk of deleterious effects during a lifetime. For chlorpyrifos, this value is equal to $0.3 \mu \mathrm{g} / \mathrm{kg}$-day [31]. The results do not present any significant difference in the exposure levels between males and females in both children and adults.

The CARES NG® Dietary Model does not output the contribution of each pesticide to the cumulative exposure. However, it is indeed interesting knowing which pesticides represent the main source of exposure and, consequently, of concern. To obtain this information, each pesticide has been analysed separately by running aggregate exposure assessments in CARES NG®. The results obtained from the aggregate assessments are summarized in Table 9. Piperonyl butoxide is the chemical with the highest exposure levels due to a combination of the high occurrence of detected values in

Table 8 Cumulative dietary multi-day exposure.

\begin{tabular}{lllll}
\hline Statistics & Children male $^{*}$ & Children female $^{*}$ & Adults male $^{*}$ & Adults female $^{*}$ \\
\hline Mean & 0.002 & 0.002 & 0.001 & 0.001 \\
\hline P95 & 0.005 & 0.004 & 0.003 & 0.003 \\
\hline P99 & 0.027 & 0.026 & 0.014 & 0.013
\end{tabular}

Chlorpyrifos used as the Index Chemical. All values given in in $\mu \mathrm{g} / \mathrm{kg}$-day. 
International Journal of Environment, Agriculture and Biotechnology, 5(2)

Available: https://ijeab.com/

Table 9 Aggregate dietary multi-day exposure.

\begin{tabular}{|c|c|c|c|c|c|}
\hline Pesticide name & Statistics & Children male* & Children female & Adults male ${ }^{*}$ & Adults female \\
\hline \multirow[t]{3}{*}{ Chlorpyrifos } & Mean & 0.001 & 0.001 & $<0.001$ & $<0.001$ \\
\hline & P95 & 0.003 & 0.003 & 0.002 & 0.002 \\
\hline & P99 & 0.008 & 0.008 & 0.004 & 0.004 \\
\hline \multirow[t]{3}{*}{ Diazinon } & Mean & 0.004 & 0.004 & 0.001 & 0.001 \\
\hline & P95 & $<0.001$ & $<0.001$ & $<0.001$ & $<0.001$ \\
\hline & P99 & 0.055 & 0.053 & 0.007 & 0.009 \\
\hline \multirow[t]{3}{*}{ Piperonyl Butoxide } & Mean & 0.015 & 0.015 & 0.013 & 0.008 \\
\hline & P95 & 0.079 & 0.081 & 0.061 & 0.043 \\
\hline & P99 & 0.189 & 0.181 & 0.119 & 0.084 \\
\hline \multirow[t]{3}{*}{ Thiamethoxam } & Mean & 0.001 & 0.001 & $<0.001$ & $<0.001$ \\
\hline & P95 & $<0.001$ & $<0.001$ & $<0.001$ & $<0.001$ \\
\hline & P99 & 0.012 & 0.011 & 0.003 & 0.005 \\
\hline \multirow[t]{3}{*}{ Novaluron } & Mean & 0.003 & 0.003 & 0.001 & 0.002 \\
\hline & P95 & 0.004 & 0.003 & $<0.001$ & $<0.001$ \\
\hline & P99 & 0.082 & 0.08 & 0.028 & 0.043 \\
\hline \multirow[t]{3}{*}{ Bifenthrin } & Mean & 0.003 & 0.003 & 0.002 & 0.002 \\
\hline & P95 & 0.013 & 0.013 & 0.007 & 0.007 \\
\hline & P99 & 0.03 & 0.03 & 0.02 & 0.019 \\
\hline \multirow[t]{3}{*}{ Azoxystrobin } & Mean & 0.003 & 0.003 & 0.002 & 0.001 \\
\hline & P95 & 0.013 & 0.012 & 0.007 & 0.007 \\
\hline & P99 & 0.028 & 0.028 & 0.018 & 0.017 \\
\hline \multirow[t]{3}{*}{ Imidacloprid } & Mean & 0.004 & 0.005 & 0.002 & 0.003 \\
\hline & P95 & 0.02 & 0.021 & 0.011 & 0.014 \\
\hline & P99 & 0.092 & 0.095 & 0.041 & 0.049 \\
\hline \multirow[t]{3}{*}{ Malathion } & Mean & $<0.001$ & $<0.001$ & $<0.001$ & $<0.001$ \\
\hline & P95 & $<0.001$ & $<0.001$ & $<0.001$ & $<0.001$ \\
\hline & P99 & 0.002 & 0.002 & $<0.001$ & 0.001 \\
\hline \multirow[t]{3}{*}{ MGK-264 } & Mean & 0.002 & 0.002 & 0.002 & 0.001 \\
\hline & P95 & 0.011 & 0.011 & 0.009 & 0.006 \\
\hline & P99 & 0.027 & 0.025 & 0.017 & 0.012 \\
\hline \multirow[t]{3}{*}{ Pyriproxyfen } & Mean & 0.001 & 0.001 & 0.001 & 0.001 \\
\hline & P95 & 0.005 & 0.005 & 0.003 & 0.002 \\
\hline & P99 & 0.012 & 0.011 & 0.007 & 0.007 \\
\hline
\end{tabular}

*All values given in in $\mu \mathrm{g} / \mathrm{kg}$-day. 
International Journal of Environment, Agriculture and Biotechnology, 5(2)

Available: https://ijeab.com/

Table 10 Contribution of each pesticide to the total cumulative exposure for the P95 consumer

\begin{tabular}{|c|c|c|c|c|}
\hline Pesticide name & Children male & Children female & Adults male & Adults female \\
\hline Chlorpyrifos & $43.02 \%$ & $43.09 \%$ & $44.07 \%$ & $48.25 \%$ \\
\hline Diazinon & $<0.01 \%$ & $<0.01 \%$ & $<0.01 \%$ & $<0.01 \%$ \\
\hline Piperonyl Butoxide & $22.66 \%$ & $23.27 \%$ & $26.88 \%$ & $20.75 \%$ \\
\hline Thiamethoxam & $<0.01 \%$ & $<0.01 \%$ & $<0.01 \%$ & $<0.01 \%$ \\
\hline Novaluron & $1.26 \%$ & $0.95 \%$ & $0.00 \%$ & $0.00 \%$ \\
\hline Bifenthrin & $12.49 \%$ & $12.51 \%$ & $10.33 \%$ & $11.31 \%$ \\
\hline Azoxystrobin & $9.32 \%$ & $8.62 \%$ & $7.71 \%$ & $8.44 \%$ \\
\hline Imidacloprid & $5.74 \%$ & $6.03 \%$ & $4.85 \%$ & $6.76 \%$ \\
\hline Malathion & $<0.01 \%$ & $<0.01 \%$ & $<0.01 \%$ & $<0.01 \%$ \\
\hline MGK-264 & $3.15 \%$ & $3.16 \%$ & $3.97 \%$ & $2.90 \%$ \\
\hline Pyriproxyfen & $2.37 \%$ & $2.37 \%$ & $2.18 \%$ & $1.59 \%$ \\
\hline
\end{tabular}

samples obtained in the PDP study and high concentration of the chemical, significantly higher than those found in the other foods shown in Table 3.

To compare the contribution of each pesticide in the overall exposure, the results had to be converted to the equivalents of the Index Chemical, here chlorpyrifos, using the Relative Potency Factors (see Methodology and Table 5). Using this conversion, the contributions were calculated for the P95 and P99 consumers, but as the results were very similar, only the contributions for the P95 consumer are presented in Table 10.

Piperonyl butoxide contributes to around $25 \%$ of the total cumulative exposure on the P95 level for all four

Table 10 Cumulative exposure from inhalation, tobacco smoking.

\begin{tabular}{llll}
\hline Pesticide name & Statistics & $\begin{array}{l}\text { Adults } \\
\text { male }\end{array}$ & $\begin{array}{l}\text { Adults } \\
\text { female* }\end{array}$ \\
\hline $\begin{array}{l}\text { All chemicals, } \\
\text { whole }\end{array}$\begin{tabular}{lll} 
population \\
\cline { 2 - 4 }
\end{tabular} & Pean & 0.00093 & 0.00075 \\
\cline { 2 - 4 } & P99 & 0.00568 & 0.00546 \\
\hline $\begin{array}{l}\text { All chemicals, } \\
\text { smokers only }\end{array}$ & Pean & 0.00380 & 0.00392 \\
\cline { 2 - 4 } & P99 & 0.00956 & 0.00933 \\
\hline
\end{tabular}

* Chlorpyrifos used as the Index Chemical.

All values given in in $\mu \mathrm{g} / \mathrm{kg}$-day. subpopulations, being the second biggest contributor after chlorpyrifos. Chlorpyrifos remains the main contributor because its degree of toxicity is higher than the other pesticides under analysis. The third most contributing pesticide is bifenthrin with contribution ranging from to $10 \%$ to $13 \%$. The order of the most contributing pesticides was the same for P99 consumers.

\section{Smoking exposure}

The results of the assessment of the exposure via inhaling cigarette smoke were compared to the No Observable Adverse Effect Level (NOAEL), which has been determined for inhalation of chlorpyrifos to be equal to $100 \mu \mathrm{g} / \mathrm{kg}$-day by US EPA [31]. The results are presented in Table 11 and they present similar exposure levels for male and female adults, all below the NOAEL values.

Table 12 reports the results obtained from the aggregate assessments for the total US adult population (smokers and nonsmokers), with the chlorpyrifos equivalent values obtained by multiplication of the exposure by the Relative Potency Factors, reported in brackets. Despite lower exposure levels, the exposure equivalent doses of parathion and terbufos are similar to the exposure levels of chlorpyrifos, due to the higher toxicity of these two pesticides. 
International Journal of Environment, Agriculture and Biotechnology, 5(2)

Available: https://ijeab.com/

Table 11 Aggregate exposure and chlorpyrifos equivalent doses from inhalation, tobacco smoking.

\begin{tabular}{llll}
\hline $\begin{array}{l}\text { Pesticide } \\
\text { name }\end{array}$ & Statistics & $\begin{array}{l}\text { Adults male (chlorpyrifos } \\
\text { equivalent dose })^{*}\end{array}$ & $\begin{array}{l}\text { Adults female (chlorpyrifos } \\
\text { equivalent dose) }\end{array}$ \\
\hline Chlorpyrifos & Mean & 0.00031 & 0.00025 \\
\cline { 2 - 4 } & P95 & 0.00188 & 0.00180 \\
\cline { 2 - 4 } & P99 & 0.00332 & 0.00304 \\
\hline Parathion & Mean & $0.00004(0.00033)$ & $0.00003(0.00025)$ \\
\cline { 2 - 4 } & P95 & $0.00023(0.00192)$ & $0.00022(0.00183)$ \\
\cline { 2 - 4 } Terbufos & P99 & $0.00040(0.00333)$ & $0.00037(0.00308)$ \\
\cline { 2 - 4 } & Pean & $0.00003(0.0003)$ & $0.00018(0.0018)$ \\
\cline { 2 - 4 } & P99 & $0.00019(0.0019)$ & $0.00031(0.0031)$ \\
\hline
\end{tabular}

*All values given in in $\mu \mathrm{g} / \mathrm{kg}$-day.

\section{Total exposure}

To calculate total cumulative exposure (food and smoking), cumulative food exposure levels were added to cumulative smoking exposure levels. As smoking was considered only regarding the adults, the exposure for children remains unchanged. The outcomes are shown in Table 13.

The exposure to pesticide residues is the highest for the smokers when the mean and P95 values are compared. For the high-consumer (P99) however, the exposure is the highest among the children. This means that children who consume high quantities of food can reach exposure levels that are even higher than those experienced by smokers.

The exposure levels for high consumers at commodity level are given in Table 14. Tomatoes are, among the foods, the commodity that presents the highest exposure levels in all the subpopulations. They are second only to the tobacco exposure levels in the adult population. According to the NHANES 2005-2010 consumption data, tomatoes contribute to $2.6 \%$ of the overall diet of children in the US and around $4.8 \%$ of the diet of adults. Of the five food commodities considered in this study, tomatoes are the most widely consumed commodity in adults, and the second most consumed for children. High consumption and relatively high number of samples containing pesticide residues recorded in the PDP are the main drivers of this result. The other four commodities show similar exposure levels that are included in the range of $0.001-0.002$ $\mu \mathrm{g} / \mathrm{kg}$-day.

Table 12 Total cumulative multi-day exposure, food and smoking.

\begin{tabular}{lllllll}
\hline Statistics & $\begin{array}{l}\text { Children } \\
\text { male* }\end{array}$ & $\begin{array}{l}\text { Children } \\
\text { female* }\end{array}$ & Adults male* & $\begin{array}{l}\text { Adults } \\
\text { female }\end{array}$ & $\begin{array}{l}\text { Adults male, } \\
\text { smokers } \\
\text { only }^{*}\end{array}$ & $\begin{array}{l}\text { Adults } \\
\text { female, } \\
\text { smokers } \\
\text { only }\end{array}$ \\
\hline Mean & 0.0020 & 0.0020 & 0.0020 & 0.0017 & 0.0049 & 0.0048 \\
\hline P95 & 0.0050 & 0.0040 & 0.0074 & 0.0068 & 0.0111 & 0.0122 \\
\hline P99 & 0.0270 & 0.0260 & 0.0186 & 0.0169 & 0.0237 & 0.0227
\end{tabular}

* Chlorpyrifos used as the Index Chemical. All values given in in $\mu \mathrm{g} / \mathrm{kg}$-day. 
International Journal of Environment, Agriculture and Biotechnology, 5(2)

Available: https://ijeab.com/

Table 13 Exposure per commodity for high consumers (99th percentile).

\begin{tabular}{lllll}
\hline Food commodity & Children male & Children female $^{*}$ & Adults male $^{*}$ & Adults female $^{*}$ \\
\hline Strawberries & 0.001 & 0.002 & $<0.001$ & 0.001 \\
\hline Tomatoes & 0.014 & 0.012 & 0.008 & 0.006 \\
\hline Lettuce & $<0.001$ & 0.001 & 0.001 & 0.002 \\
\hline Apples & 0.003 & 0.002 & $<0.001$ & $<0.001$ \\
\hline Rice & 0.002 & 0.002 & 0.002 & 0.002 \\
\hline Tobacco & - & - & 0.010 & 0.009
\end{tabular}

*All values given in in $\mu \mathrm{g} / \mathrm{kg}$-day.

\section{DISCUSSION}

This study successfully developed a new framework that allows us to assess the cumulative exposure to pesticides from concurrent sources, in this case ingestion of foods and smoked tobacco. Additionally, the output obtained from applying this framework to real-world data presented some interesting results.

The analysis suggests that, at population level, the exposure to pesticide residues is approximately two times higher in children than in adults. Children's exposure levels are higher than adults' even when accounting for smoking in adults. That is due to the fact that children's consumption of foods per unit of body weight is more than twice larger than adults (note that the body weight of children is substantially smaller than adults). According to the NHANES 2005-2015 consumption data, children consume on average $38.5 \mathrm{~g}$ of food per $\mathrm{kg}$ of bodyweight, whereas adults - $14.9 \mathrm{~g} / \mathrm{kg}$ of bodyweight. Children eat, on average, amounts of foods that are similar to the amounts consumed by adults; however, their bodyweight is significantly lower, which results in their relative exposure being much higher than the exposure among adults.

The food commodity contributing to the most exposure to pesticide residues for the high consumer are tomatoes, which contribute to around $2.6 \%$ to overall diet of children in the US and around $4.8 \%$ of diet of adults. This is followed by apples and rice in children (each contributing to less than $1 \%$ of children diet) and by rice in adults (contributing to about $1.6 \%$ of the overall adult diet). Another key observation is that children who are high-consumers of foods (at P99 level) can reach exposure levels that are even higher than those experienced by the smokers.
The exposure levels estimated by the CARES NG® dietary model are lower than the cRfD for oral exposure to chlorpyrifos equal to $0.3 \mu \mathrm{g} / \mathrm{kg}$-day, even at P99 level $(0.9 \%$ of cRfD for children, $0.47 \%$ of cRfD for adults). This means that at least $99 \%$ of the US population is exposed to doses of pesticides that are not of concern for their health.

Focusing on adults only, exposure to pesticide residues in tobacco and food is more than twice as high among smokers than non-smokers. On the population level, that is including smokers and non-smokers, smoking cigarettes does not change the overall exposure significantly, due to only about $20 \%$ of the adult population being smokers and $100 \%$ of the population being food consumers. However, the difference is clear when comparing the results for the whole population and smokers only, indicating how high the additional risk of inhaling pesticide residues is from smoking cigarettes. According to our analysis, the high consumers of cigarettes are exposed to almost $0.016 \mu \mathrm{g} / \mathrm{kg}$-day of all three pesticides analysed for smoking in this study. To our knowledge, this is the first attempt to quantify the exposure levels to pesticide residues from smoking tobacco.

The two-box model preserves a conservative approach, using Guidance Residue Levels (GRLs) to approximate the real residue levels in tobacco, which are likely to be higher than the actual residue concentrations. The amounts inhaled during smoking cigarettes are lower than the NOAEL (about $0.016 \%$ of NOAEL for smokers on P99 level). However, the regulatory bodies that decide on the NOAEL level do not conduct studies on the effect of the pesticides that would be smoked. The pesticides in cigarettes may undergo the process of pyrolysis during smoking [32], meaning that the chemical might change its composition in the high temperatures and be more harmful than non-smoked compounds. Hence any 
comparison between the NOAEL and the amounts of pesticides inhaled while smoking should be carried out with caution.

The results also show no significant differences in the cumulative exposure levels between male and female smokers, even though the number of cigarettes for the high percentiles is bigger for men than women. The reason for that is the body weight of men tends to be larger than the body weight of women, so per unit body weight exposure is in the end similar. In this project, we analysed the exposure to pesticide in tobacco only for people who are active smokers, however second-hand smokers are also at risk of being exposed to these chemicals, especially those living with people who smoke cigarettes indoors.

In all scenarios analysed, the cumulative exposure was below the regulatory limits that were considered suitable to this study, namely the No-Observable-Adverse-Effect-Level for the inhalation exposure (tobacco) and the Chronic Reference Dose for the oral exposure (foods). Overall exposure to each of these pesticides might be higher, as the presented study looked only at the specific food groups, contributing overall to less than $15 \%$ of a typical American diet (based on the NHANES population), as shown in Table 7 in the Results section. Moreover, only a limited number of pesticides was analysed. It is likely that the US population is exposed to higher quantities of pesticides coming from the rest of the diet. Therefore, this analysis cannot be used to infer any risk for the health of the US population, but it provides a framework to assess exposure to pesticides from different sources by combining the results from multiple models.

A study analysing the total diet of the US population and all the pesticides currently used in the USA would be very complex and adversely helpful in risk analysis. It would be difficult to determine the main factors that contribute to the total cumulative exposure because of the number of pesticides available on the US market and their different degrees of toxicity. Despite its limitation, the results obtained from this exposure analysis present interesting trends that are worth highlighting, especially in the light of previously neglected exposures to pesticides residues from tobacco leaves.

The lack of a publicly available monitoring pesticide residue data on tobacco crops was another hindrance to this study. Using such monitoring data would provide a more refined analysis of the exposure levels among the smokers. Moreover, tobacco is not the only commodity that is smoked by consumers. Marijuana is, to date, legal in 33 states of the US for medical purposes and in 10 for recreational purposes. It has been shown, that pesticide residues in marijuana are directly transferred into the mainstream smoke and as a result inhaled by the smoker [33]. Medical marijuana is often smoked by patients suffering from various health conditions, such as cancer or AIDS, particularly prone to chemical poisoning [33]. Recreational marijuana on the other hand is often smoked without a filter, providing no protection from the pesticide residues to the smokers. More data on the marijuana consumptions and programs monitoring the pesticide levels on marijuana and tobacco leaves would enable to expand the current analysis even further.

\section{CONCLUSIONS}

This study presents a novel methodology for assessing the exposure to pesticide residues in dietary sources and tobacco. The analysis suggests that although all exposure levels are below the regulatory limits, the exposure among children is higher than exposure among the adults. Moreover, the exposure to pesticide residues in the adult population is twice as high for smokers than non-smokers. Among the 11 pesticides analysed, chlorpyrifos was the pesticide causing the highest exposure levels.

The model described in this manuscript provides a new general framework, that can be used to assess the impact of a new pesticide on the population in a broader spectrum than the models typically used for such purpose. To our knowledge, it is the first model that combines the estimation of the pesticide exposure from the diet and smoking cigarettes. The importance of such tool is even more substantial now with the marijuana becoming legalised in more parts of the world. However, more monitoring data is needed to refine the assessments.

\section{ABBREVIATIONS}

CARES NG®: Cumulative and Aggregate Risk Evaluation System Next Generation

CORESTA: Cooperation Centre for Scientific Research Relative to Tobacco

cRfD: Chronic Reference Dose

EPA: Environmental Protection Agency

FCID: Food Commodity Intake Database

GRL: Guidance Residue Level

MRL: Maximum Residue Level 
NCHS: National Centre for Health Statistics

NHANES: National Health and Nutrition Examination Survey

NOAEL: No Observed Adverse Effects Level

OPP: Office of Pesticide Programs

OP: Organophosphate pesticide

P95,P99: $95^{\text {th }}, 99^{\text {th }}$ percentile

PDP: Pesticide Data Program

POD: Point of Departure

RAC: Raw Agricultural Commodity

RIFM: Research Institute of Fragrance Materials

RPF: Relative Potency Factor

WWEIA: What We Eat In America

\section{Declarations}

\section{Availability of data and material}

The datasets used in the current study are available online from:

FCID:http://fcid.foodrisk.org/

NHANES:https://www.cdc.gov/nchs/nhanes/index.htm

PDP:https://www.ams.usda.gov/datasets/pdp

\section{Competing interests}

LMG consults for Microbide Limited. MGS is employed by Microbide Limited.

\section{Funding}

This research was supported by Microbide Limited.

\section{Authors' contributions}

LMG participated in the study design, was involved in the interpretation of the results and worked on the manuscript. MGS participated in the study design. All authors read and approved the final manuscript.

\section{ACKNOWLEDGEMENTS}

CremeGlobal (Ireland) provided an independent data analytics service.

\section{REFERENCES}

[1] Cole DC, Kaur JS, Kerr KJ, Bassil KL, Vakil MC, Fcfp C, Sanborn M. Cancer health effects of pesticides Systematic review. Can Fam Physician. 2007; 53:1704-1711.

[2] Sanborn M, Kerr K.J, Sanin L.H, Cole D.C, Bassil K.L, Vakil C. Non-cancer health effects of pesticides Systematic review and implications for family doctors. Can Fam Physician. 2007; 53:1712-1720

[3] Kim K-H, Kabir E, Jahan SA. Exposure to pesticides and the associated human health effects. Sci Total Environ. 2017; 575:525-535. doi:10.1016/j.scitotenv.2016.09.009.

[4] Federal Insecticide, Fungicide, and Rodenticide Act (7 U.S.C. 136 et seq.)(FIFRA), Title 40 - Pretection of Environment, Chapter I - Environmental Protection Agency, Subchapter E Pesticide Programs, Part 152 - Pesticide Registration and Classification Procedures.https://www.ecfr.gov/cgi-bin/textidx?SID=72074de9d6c881ae57a281af71 f8c204\&mc=true \&no $\mathrm{de}=\mathrm{pt} 40.24 .152 \& \mathrm{rgn}=\mathrm{div} 5 \#$ sp40.26.152.i. Accessed 10Dec 2018.

[5] National Research Council. Pesticides in the Diets of Infants and Children. Washington, DC: The National Academies Press. 1993. doi:10.17226/2126.

[6] Damalas CA, Eleftherohorinos IG. Pesticide Exposure, Safety Issues, and Risk Assessment Indicators. Int J Environ Res Public Health. 2011; 8:1402-1419.doi:10.3390/ijerph8051402.

[7] Roberts JR, Karr CJ, Council On Environmental Health. Pesticide exposure in children. Pediatrics.2012; 130:e1765-88. doi:10.1542/peds.2012-2758.

[8] US EPA. Pesticides Industry Sales and Usage 2008 - 2012. U.S Environmental Protection Agency, Washington DC. 2017.

[9] Barr DB, Wong L-Y, Bravo R, et al. Urinary concentrations of dialkylphosphate metabolites of organophosphorus pesticides: National Health and Nutrition Examination Survey 1999-2004. Int $\mathrm{J}$ Environ Res Public Health. 2011; 8:3063-98. doi:10.3390/ijerph8083063.

[10] Morgan MK, Jones PA. Dietary predictors of young children's exposure to current-use pesticides using urinary biomonitoring. Food Chem Toxicol. 2013; 62:131-41. doi:10.1016/j.fct.2013.08.029.

[11] Curl CL. Characterizing Dietary Exposure to Organophosphate Pesticides, Incorporating Organic Food Consumption, for Use in Epidemiological Research. 2014.

[12] Rauh VA, Garfinkel R, Perera FP, Andrews HF, Hoepner L, Barr DB, Whitehead R, Tang D, Whyatt RW. Impact of prenatal chlorpyrifos exposure on neurodevelopment in the first 3 years of life among inner-city children. Pediatrics. 2006; 118:e1845-59. doi:10.1542/peds.2006-0338.

[13] Gunier RB, Bradman A, Harley KG, Kogut K, Eskenazi B. Prenatal Residential Proximity to Agricultural Pesticide Use and IQ in 7-Year-Old Children. Environ Health Perspect. 2017; 125:057002. doi:10.1289/EHP504.

[14] League of United Latin American Citizens. On Petition for Review of an Order of the Environmental Protection Agency. Seattle, Washington. August 2018.

[15] Winter CK. Chronic dietary exposure to pesticide residues in the United States. Int J Food Contam. 2015; 2:11. 
doi:10.1186/s40550-015-0018-y.

[16] USGS NAWQA: The Pesticide National Synthesis Project. https://water.usgs.gov/nawqa/pnsp/usage/maps/about.php. Accessed 12 Oct 2018

[17] Guthrie FE, Bowery TG. Pesticide residues on tobacco. Residue Rev. Springer New York. 1967; pp 31-56. doi:10.1007/978-1-4615-8425-4_3.

[18] Chapman S. "Keep a low profile": pesticide residue, additives, and freon use in Australian tobacco manufacturing. Tob Control. 2003; 12:iii45-iii53. doi:10.1136/tc.12.suppl_3.iii45.

[19] Raber JC, Elzinga S, Kaplan C. Understanding dabs: Contamination concerns of cannabis concentrates and cannabinoid transfer during the act of dabbing. J Toxicol Sci. 2015; 40:797-803. doi:10.2131/jts.40.797\}

[20] CARES NG. http://caresng.org/. Accessed 1 Oct 2018.

[21] RIFM Innovative Model Calculates Inhalation Exposure To Fragrance Materials. https://www.prnewswire.com/newsreleases/rifm-innovative-model-calculates-inhalationexposure-to-fragrance-materials-150024785.html. Accessed 1 Oct 2018.

[22] NHANES - National Health and Nutrition Examination Survey Homepage. https://www.cdc.gov/nchs/nhanes/. Accessed 1 Oct 2018.

[23] Pesticide Data Program | Agricultural Marketing Service. https://www.ams.usda.gov/datasets/pdp. Accessed 1 Oct 2018.

[24] What We Eat In America - Food Commodity Intake Database. http://fcid.foodrisk.org/. Accessed 20 Nov 2018.

[25] GAO. Pesticides on Tobacco. Federal Activities to Assess Risks and Monitor Residues. Washingtion DC, 2003.

[26] CORESTA - Agrochemical Guidance Residue Levels (GRLs). https://www.coresta.org/agrochemical-guidance-residuelevels-grls-29205.html. Accessed 1 Oct 2018.

[27] US EPA, Office of Pesticide Programs. Consideration of the FQPA Safety Factor and Other Uncertainty Factors in Cumulative Risk Assessment of Chemicals Sharing a Common Mechanism of Toxicity. Washington DC. 2002.

[28] US EPA, Office of Pesticide Programs. General Principles For Performing Aggregate Exposure And Risk Assessments. U.S Environmental Protection Agency, Washington DC. 2001.

[29] US EPA. Exposure Factors Handbook 2011 Edition (Final Report). U.S Environmental Protection Agency, Washington DC, EPA/600/R-09/052F. 2011.

[30] Harris B. The intractable cigarette 'filter problem'. Tobacco Control. 2011;20:i10-i16.doi:10.1136/tc.2010.040113.

[31] US EPA, Office of Pesticide Programs. Reregistration Eligibility Decision for Chlorpyrifos. U.S Environmental Protection Agency, Washington DC. 2006.

[32] Lorenz W, Bahadir M, Korte F. Thermolysis of Pesticide Residues During Tobacco Smoking. Chemosphere.1987;16:521-522.

[33] Sullivan N, Elzinga S, Raber JC. Determination of pesticide residues in cannabis smoke. J Toxicol 2013;378168. doi:10.1155/2013/378168. 